\title{
MINIMYCIN, A NEW ANTIBIOTIC
}

\author{
Yohko Kusakabe, Junsaku Nagatsu, Mitsuo Shibuya, \\ Osamu Kawaguchi, Chieko Hirose \\ and Shiroh Shirato
}

Research Division of the Kaken Chemical Co., Ltd., Tokyo, Japan

(Received for publication September 11, 1971)

\begin{abstract}
A new crystalline antibiotic, minimycin ${ }^{1)}, \mathrm{C}_{9} \mathrm{H}_{11} \mathrm{NO}_{7}$, was isolated from the culture broth of Streptomyces hygroscopicus. Isolation and properties of the new antibiotic are described. Minimycin is active against both Gram-positive and Gram-negative bacteria, and also possesses significant antitumor activity against transplantable tumors.
\end{abstract}

During the course of our screening program for new antibiotics, Streptomyces sp. 80432 isolated from a soil sample was found to produce a water-soluble antibiotic. This antibiotic, named minimycin, showed not only inhibitory activity against Grampositive and Gram-negative bacteria, but also antitumor activity. Isolation and purification by a chromatography gave a colorless crystalline substance as needles or prisms. The physical, chemical and biological properties of minimycin were examined, and it was found to be a new antibiotic. This paper describes the fermentation production, isolation procedures, and characterization of minimycin together with its antimicrobial and antitumor activities.

\section{Antibiotic Production}

Streptomyces sp. 80432 was isolated from a soil sample collected at Nyugawa, Ehime Prefecture, Japan, and identified as Streptomyces hygroscopicus. The antibiotic minimycin was produced in a medium composed of glucose $4.0 \%$, soy bean meal $2.0 \%$, wheat embryo $1.0 \%$, brewer's yeast $0.4 \%$, sodium chloride $0.2 \%$, potassium chloride $0.2 \%$ and calcium carbonate $0.2 \%$, at $\mathrm{pH} 6.8$ before sterilization. Fermentation was carried out in a stirred-jar fermenter for $48 \sim 60$ hours at $27^{\circ} \mathrm{C}$.

\section{Isolation and Purification}

The antibiotic was isolated from the culture filtrate; no activity was demonstrated in the mycelium. A procedure for preparation of minimycin is as follows: The cultured broth filtrate (100 liters) was acidified to $\mathrm{pH} 2.0$ with $10 \%$ hydrochloric acid, treated with active carbon $(2.0 \mathrm{~g}$ per $100 \mathrm{ml})$, and the mixture was stirred for 30 minutes. The carbon cake was filtered, washed with water, and eluted with $50 \%$ aqueous acetone. The elution was repeated three times with the same solvent, and the combined eluate was concentrated under reduced pressure to a small volume. The concentrate was then chromatographed on a carbon column, and developed with $10 \%$ aqueous acetone after washing with water. The active fraction, eluted with $20 \%$ 
aqueous acetone, was collected, and concentrated in vacuo to a small volume.

Crude minimycin ( $4 \mathrm{~g}$ ) was purified by Sephadex G-15 chromatography in water. The active fraction detected by assay using Staphylococcus aureus FDA $209 \mathrm{P}$ was collected, and concentrated under reduced pressure. This active concentrate was again applied to a column of Sephadex G-10, developing with water. The active fraction was concentrated under reduced pressure and finally freeze-dried.

The colorless powder thus obtained was recrystallized either from water or from water-miscible organic solvents (e.g. ethanol, methanol, acetone etc.). Recrystallization from water gave needles melting at $166^{\circ} \mathrm{C}$, and from the other solvents prisms melting at $161^{\circ} \mathrm{C}$ were obtained. The total yield was $2 \mathrm{~g}$.

\section{Physical and Chemical Properties}

Physical and chemical properties of minimycin are summarized in Table 1. Fig. 1 shows the infrared absorption in $\mathrm{KBr}$ of minimycin in the needle form and Fig. 2 the spectrum of minimycin in the prism form. The nuclear magnetic resonance spectrum of minimycin in deuterium oxide is shown in Fig. 3.

The above properties of minimycin are similar to those of showdomycin ${ }^{2,3}$. However, minimycin differs from showdomycin with respect to molecular formula, ultraviolet absorption spectrum and infrared absorption spectrum. Thus, the antibiotic minimycin differs from all known antibiotics, and is a new antibiotic. The structural investigation will be reported in near future.

\section{Biological Activity}

Table 2 shows the antimicrobial spectrum of minimycin using diffusion techniques on bouillon and glycerine bouillon agar. Minimycin is active against Gram-positive and Gram-negative bacteria, but has no activity against yeasts and fungi.

Table 1. Physical and chemical properties of minimycin.

\begin{tabular}{|c|c|}
\hline Appearance & Colorless needles or prisms \\
\hline Melting point (dec.) & $\begin{array}{l}161^{\circ} \mathrm{C} \text { (prisms) } \\
166^{\circ} \mathrm{C} \text { (needles) }\end{array}$ \\
\hline Solubility & $\begin{array}{l}\text { Soluble in water, methanol } \\
\text { Slightly soluble in ethanol, propanol, acetone } \\
\text { Insoluble in benzene, hexane, ether }\end{array}$ \\
\hline Optical rotation & {$[\alpha]_{\mathrm{D}}^{25}+18^{\circ}(c 1$, water $)$} \\
\hline Ultraviolet absorption & Inflection at $230 \mathrm{~m} \mu\left(\mathrm{E}_{1 \mathrm{~cm}}^{1 \%} \quad 188.0\right)$ in $0.01 \mathrm{~N} \mathrm{HCl}$ \\
\hline Color reaction & $\begin{array}{l}\text { Positive : hydroxamic acid- } \mathrm{FeCl}_{3}, \mathrm{BALJET} \text { oxyvanadium-salt, } \\
\mathrm{KMnO}_{4} \text { (decolorized) } \\
\text { Negative : ninhydrin, ELsoN-MorGAN, biuret, tetrazolium } \\
\text { chloride, ferric chloride }\end{array}$ \\
\hline Molecular weight & 245 (vapor pressure osmometry) \\
\hline Elemental analysis & $\begin{array}{r}\text { Found : } \mathrm{C} 44.15, \mathrm{H} 4.62, \mathrm{~N} 5.84, \text { O } 45.39 \% \\
\text { Calcd. for } \mathrm{C}_{9} \mathrm{H}_{11} \mathrm{NO}_{7}: \mathrm{C} 44.08, \mathrm{H} 4.57, \mathrm{~N} 5.71, \text { O } 45.68 \%\end{array}$ \\
\hline Rf values on silica gel TLC & $\begin{array}{ll}\text { wet } \mathrm{BuOH} & 0.42 \\
\mathrm{BuOH}-\mathrm{AcOH}-\mathrm{H}_{2} \mathrm{O}(4: 1: 2) & 0.57 \\
\text { EtOH-H } \mathrm{H}_{2} \mathrm{O}(4: 1) & 0.75 \\
\mathrm{CHCl}_{3}-\mathrm{MeOH}-17 \% \mathrm{NH}_{4} \mathrm{OH}(2: 1: 1) \text { upper } & 0.88 \\
\text { PrOH-Pyr-AcOH}-\mathrm{H}_{2} \mathrm{O}(15: 10: 3: 12) & 0.85\end{array}$ \\
\hline Stability & $\begin{array}{l}\text { Stable in acidic and neutral media } \\
\text { Unstable in alkaline medium }\end{array}$ \\
\hline
\end{tabular}


Fig. 1. Infrared absorption spectrum of minimycin in needle form (KBr).

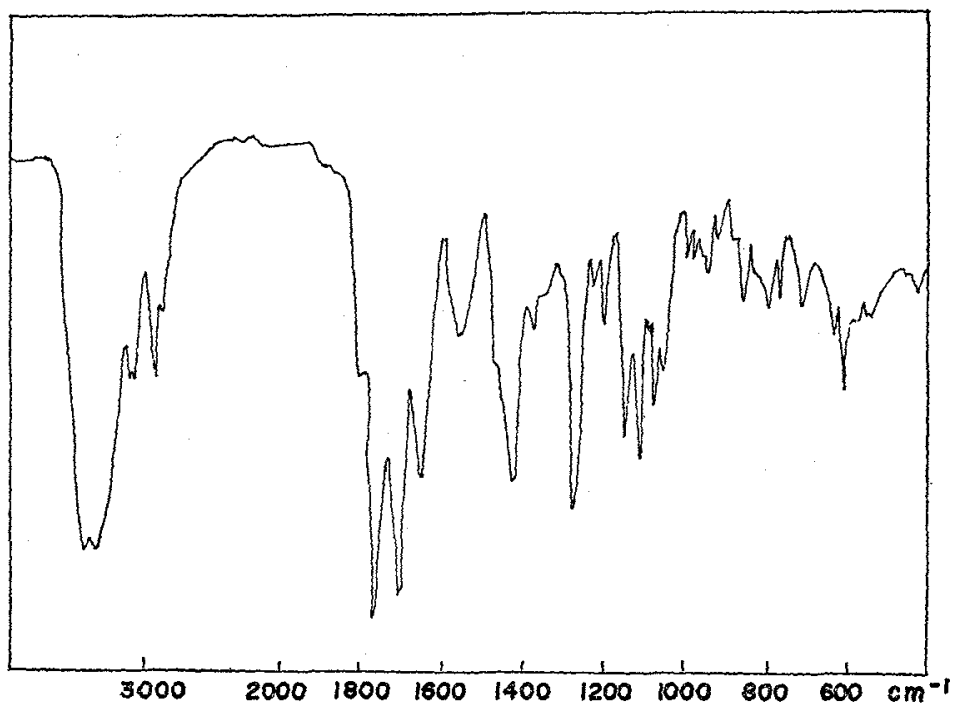

Fig. 2. Infrared absorption spectrum of minimycin in prism form (KBr).

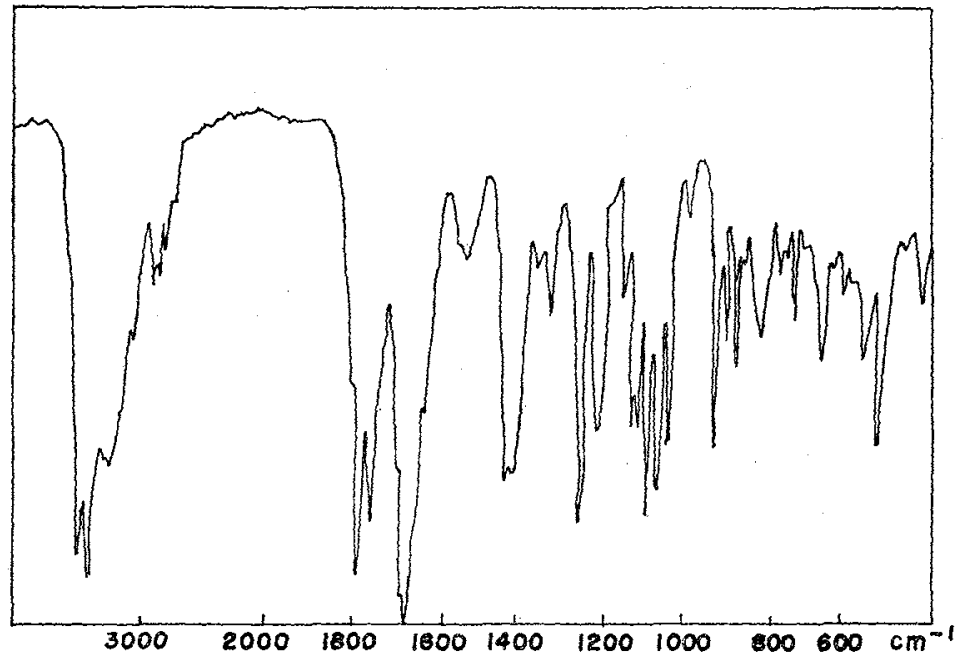

Fig. 3. Nuclear magnetic resonance spectrum of minimycin $\left(\mathrm{D}_{2} \mathrm{O}\right)$.

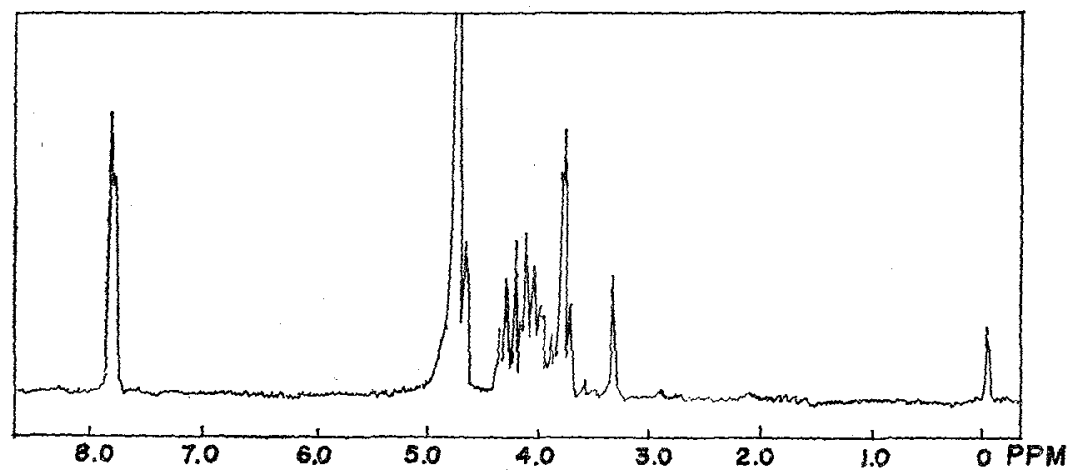


Table 2. Antimicrobial spectrum of minimycin.

\begin{tabular}{l|c|c|c}
\hline \multirow{2}{*}{ Test organisms } & \multicolumn{3}{|c}{ Inhibition zone diameter (mm) } \\
\cline { 2 - 4 } & $100 \mathrm{mcg} / \mathrm{ml}$ & $50 \mathrm{mcg} / \mathrm{ml}$ & $25 \mathrm{mcg} / \mathrm{ml}$ \\
\hline Bacillus subtilis & 27.0 & 25.0 & 23.0 \\
Staphylococcus aureus (sensitive) & 24.0 & 20.5 & 17.5 \\
(resistant)* & 24.5 & 21.5 & 18.5 \\
Escherichia coli (sensitive) & 19.6 & 17.5 & 15.5 \\
(resistant)** & 17.0 & 15.0 & 13.0 \\
\hline
\end{tabular}

* Resistant to penicillin, chloramphenicol, tetracycline, erythromycin, kanamycin, streptonycin and sulfonamide.

** Resistant to chloramphenicol, tetracycline, kanamycin, streptomycin and sulfonamide.

The acute toxicity of minimycin in mice was examined by intravenous, intraperitoneal and subcutaneous routes of administration. The $\mathrm{LD}_{50}$ for mice was $30 \mathrm{mg} /$ $\mathrm{kg}$ intraperitoneally, $20 \mathrm{mg} / \mathrm{kg}$ subcutaneously and $80 \mathrm{mg} / \mathrm{kg}$ intravenously.

The antitumor activity of minimycin was examined against EHrurch ascites carcinoma, sarcoma 180 (ascites) and sarcoma 180 (solid form) in mice. In the case of the ascites form of EHRLich carcinoma, inhibition of the tumor growth was observed by intraperitoneal in jection at a daily dose of $2 \mathrm{mg} / \mathrm{kg}$ for 10 days. The effects on the ascites form of sarcoma 180 and sarcoma 180 (solid form) were similar to those observed in the case of EhrLich carcinoma.

\section{References}

1) Kusatabe, Y.; J. Nagatsu, M. Shrbuya, O. Kawaguchi, C. Hirose \& S. Shirato: Reported at the 45 th Annual Meeting of Agr. Chem. Soc. of Japan, April 2, 1970

2) Nishimura, H.; M. Mayama, Y. Komatsu, H. Kato, N. Shimaoka \& Y. Tanaka: Showdomycin, a new antibiotic from a Streptomyces sp. J. Antibiotics, Ser. A $17: 148 \sim 155,1964$

3) Nakagawa, Y.; H. Kano, Y. TsukUda \& H. Koxama: Structure of a new class of C-nucleoside antibiotic, showdomycin. Tetrahedron Letters 1967-42:4105 4109, 1967 